\title{
ESTUDOS SOBRE O PATRIMÔNIO MODERNO, A FORMA URBANA E 0 DESEMPENHO AMBIENTAL
}

\section{STUDIES ON MODERN HERITAGE, URBAN FORM AND ENVIRONMENTAL PERFORMANCE}

\author{
Letícia de Oliveira Neves ${ }^{1}$ \\ Universidade Estadual de Campinas, \\ Faculdade de Engenharia Civil, Arquitetura \\ e Urbanismo, \\ Campinas - SP \\ Editor Chefe \\ leticia@ffec.unicamp.br \\ Daniel de Carvalho Moreira ${ }^{2}$ \\ Universidade Estadual de Campinas, \\ Faculdade de Engenharia Civil, Arquitetura \\ e Urbanismo, \\ Campinas - SP \\ Editor Chefe \\ danmore@,fec.unicamp.br \\ Sidney Piochi Bernardini ${ }^{3}$ \\ Universidade Estadual de Campinas, \\ Faculdade de Engenharia Civil, Arquitetura \\ e Urbanismo, \\ Campinas - SP \\ Editor Chefe \\ sidpiochi@fec.unicamp.br \\ Regina Coeli Ruschel ${ }^{4}$ \\ Universidade Estadual de Campinas, \\ Faculdade de Engenharia Civil, Arquitetura \\ e Urbanismo, \\ Campinas - SP \\ Editor Chefe \\ parc@fec.unicamp.br
}

\section{Editorial}

O presente número, segundo do ano de 2017, apresenta artigos de autores dos estados brasileiros da Paraíba, de São Paulo, Paraná e Santa Catarina. A diversidade de instituições de origem dos autores abrange a Universidade Federal da Paraíba, a Universidade Estadual de Campinas, a Universidade de São Paulo, a Universidade Federal do Paraná e a Universidade Federal de Santa Catarina. As áreas de formação envolvidas concentram-se em Arquitetura e Urbanismo interagindo com a Engenharia Civil, Ciências Biológicas e Engenharia Mecânica. São apresentados estudos que abordam a preservação e recuperação do patrimônio moderno, implicações do mercado imobiliário no território urbano, a forma urbana e arquitetônica e a ocorrência de crimes, telhados verdes auxiliando a manutenção da biodiversidade urbana e o potencial de redução do consumo de energia numa edificação influenciado pelo material com mudança de fase na parede externa. Desta forma, as temáticas de patrimônio, forma urbana e desempenho energético compõem as discussões e novos conhecimentos apresentados neste número.

O primeiro artigo desta edição da PARC de autoria de Regina Andrade Tirello e Ana Cynthia Sampaio Costa, da Universidade Estadual de Campinas, discute o reconhecimento dos valores históricos, artísticos e memoriais do patrimônio moderno sob o ponto de vista da preservação e recuperação física considerando as recomendações internacionais. Toma-se como objeto de discussão a Vila Serra do Navio, uma company-town localizada no Estado do Amapá, no meio da selva amazônica, tombada pelo IPHAN em 2011 como patrimônio cultural. Verifica-se que conservação da arquitetura moderna requer instruções que garantam a sobrevivência de edifícios e conjuntos no tempo.

O artigo dos autores Beatriz del Carmen Martinez González, da Universidade Estadual de Campinas, e Leandro Silva Medrano, da Universidade de São Paulo, apresenta uma reflexão acerca dos processos de transformação territorial pelos quais passam as metrópoles contemporâneas. Fenômenos como os das bolhas imobiliárias estão relacionados com a formação artificial de um mercado imobiliário promissor, como o que ocorreu na Espanha nos últimos anos. Para observar-se tal fenômeno ocorreu de forma semelhante em São Paulo,

\section{How to cite this article:}

NEVES, Letícia de Oliveira et al. Estudos sobre o patrimônio moderno, a forma urbana e o desempenho ambiental. PARC Pesquisa em Arquitetura e Construção, Campinas, SP, v. 8, n. 2, p. 73-74, jun. 2017. ISSN 1980-6809. Disponível em:

<https://periodicos.sbu.unicamp.br/ojs/index.php/parc/article/view/8651297/17401>. Acesso em: 21 dez. 2017.

doi:http://dx.doi.org/10.20396/parc.v8i2.8651297. 
o artigo busca traçar um paralelo entre processos de urbanização de novos territórios semelhantes, como os Programas de Atuacción Urbanistica (PAUs) de Madrid, e as Operações Urbanas em São Paulo, concluindo, através da análise de um conjunto de indicadores econômicos que São Paulo sofreu uma bolha imobiliária, manifestada principalmente pela expressiva subida de preços de imóveis entre 2005 e 2015, seguida de uma crise imobiliária. $\mathrm{O}$ artigo conclui que os projetos urbanos e os programas habitacionais impulsionaram tal fenômeno, sem dar cabo às soluções aos problemas urbanos presentes nestas metrópoles.

Mariana Soares, Gabriel George Grosskopf, Julia Roberta Eli, Renato Tibiriçá de Saboya e Fernando Barth, da Universidade Federal de Santa Catarina, analisam a relação entre a forma urbana e arquitetônica e a ocorrência de crimes especificamente para estacionamentos em campus universitário. Foi desenvolvido um estudo de campo comparativo entre estacionamentos com quantidades semelhantes de vagas e quantidades contrastantes de crimes. As conclusões trazem elementos para fomentar os debates, planos e intervenções em campi universitários sob a lógica da segurança.

O artigo de Tatyane Nadja Martins de Mendonça e Aluísio Braz de Melo, da Universidade Federal da Paraíba, apresenta um estudo sobre telhado verde extensivo modular que identifica a biodiversidade e as interações entre os módulos e os vegetais cultivados. Realizou-se um experimento em campo na condição de clima tropical quente e úmido. Os resultados demonstraram que plantas medicinais se adaptaram bem ao material e ao projeto do módulo sendo apresentadas orientações quanto a manutenção e irrigação. Confirmou-se a capacidade do telhado verde em auxiliar na manutenção da biodiversidade urbana.

O último artigo desta edição é de autoria de Vinicius Pons, e George Stanescu, da Universidade Federal do Paraná. O artigo apresenta um experimento simulado por análise numérica para avaliar o potencial de redução do consumo de energia para um escritório comercial com operação diurna em um edifício com estrutura de concreto armado e envoltória em alvenaria, locado em oito cidades de diferentes regiões do Brasil, utilizando-se material com mudança de fase especificado na parede externa. Os resultados comprovam que os materiais com mudança de fase podem sim, em certas condições climáticas, reduzir o consumo de energia na manutenção do conforto térmico em ambientes construídos. O emprego de sistemas inteligentes, de troca de calor e condicionamento de ar otimizado apresentaram valores significativos de redução do consumo atual de energia.

\section{Agradecimentos}

Agradecemos aos avaliadores pelo tempo despendido e valiosas considerações tecidas sobre os artigos submetidos.

\section{${ }^{1}$ Letícia de Oliveira Neves}

Arquiteta Urbanista. Doutora em Arquitetura, Tecnologia e Cidade pela Universidade Estadual de Campinas. Professora Doutora na Faculdade de Engenharia Civil, Arquitetura e Urbanismo da UNICAMP. Endereço postal: Av. Albert Einstein, 951, Campinas, SP, Brasil, CEP 13.083-852.

\section{${ }^{2}$ Daniel de Carvalho Moreira}

Arquiteto Urbanista. Doutor em Engenharia Civil (UNICAMP). Professor Doutor II na Faculdade de Engenharia Civil, Arquitetura e Urbanismo da UNICAMP. Endereço postal: Av. Albert Einstein, 951, Campinas, SP, Brasil, CEP 13.083-852.

\section{${ }^{3}$ Sidney Piochi Bernardini}

Arquiteto Urbanista. Doutor em Arquitetura e Urbanismo (FAU-USP). Professor Doutor na Faculdade de Engenharia Civil, Arquitetura e Urbanismo da UNICAMP. Endereço postal: Av. Albert Einstein, 951, Campinas, SP, Brasil, CEP 13.083-852.

\footnotetext{
${ }^{4}$ Regina Coeli Ruschel

Engenheira Civil. Doutor em Engenharia Elétrica e da Computação (UNICAMP). Livre Docente em Projeto Auxiliado por Computador (UNICAMP). Professora e Pesquisadora Colaboradora (FEC-UNICAMP) Endereço postal: Av. Albert Einstein, 951, Campinas, SP, Brasil, CEP 13.083-852.
} 